\title{
Overactive bladder symptoms recurrence after sudden versus gradual weaning of Solifenacin
}

\author{
Ahmed Abdelbary ${ }^{{ }^{*}}\left(\mathbb{D}\right.$, Ahmad Aref Al-Dessoukey ${ }^{1}$, Ayman Salah Moussa ${ }^{1}$, Mohamed Saif El-nasr², \\ Akrm Ahmed Elmarakbi ${ }^{1}$, Ahmed Medhat Ragheb ${ }^{1}$, Ahmed Mohamed Elbatanouny ${ }^{1}$, Ahmed Abdellateef ${ }^{1}$, \\ Osama Sayed ${ }^{1}$, Amr Lotfy' ${ }^{1}$ Khaled Mohyelden², Amr Mohamad Abdelhamid ${ }^{3}$, Ehab Mohamad Galal ${ }^{3}$, \\ Amr Massoud ${ }^{1}$ and Rabie M. Ibrahim ${ }^{1}$
}

\begin{abstract}
Background: To evaluate and compare the recurrence rate of overactive bladder (OAB) symptoms after solifenacin treatment in patients who stop the drug suddenly versus those who gradually wean the drug after improvement of their condition.

Methods: Our study included 60 patients with idiopathic $O A B$ and treated with solifenacin $5 \mathrm{mg}$ twice daily for one month. After improvement of their condition, we divided the responders into two groups, group I stopped the drug suddenly, while group II underwent gradual weaning of the drug.

Results: The recurrence rate of symptoms of OAB was $33.3 \%$ and $60 \%$ after 1 and 3 months in patients who stopped the solifenacin suddenly after improvement of their symptoms, while it was $6.7 \%$ and $23.3 \%$ after 1 and 3 months in patients who gradually weaned solifenacin.

Conclusion: After the improvement of OAB symptoms, gradual weaning of solifenacin can help in decreasing the recurrence rate of symptoms.
\end{abstract}

Keywords: OAB, Antimuscarinic, Recurrence of symptoms, Sudden stopping, Gradual weaning of solifenacin

\section{Background}

The International Continence Society (ICS) defines $\mathrm{OAB}$ as the complaint of urinary urgency, which may be accompanied by frequency and nocturia, with or without urgency urinary incontinence, in the absence of urinary tract infection (UTI) or other obvious pathology [1].

$\mathrm{OAB}$ causes a major burden for both patients and physicians. It is widespread in the world (ranges from $15 \%$ to $20 \%$ of middle age population). Idiopathic OAB should be properly diagnosed, because several conditions may

\footnotetext{
*Correspondence: ahmedabdelbary2010@hotmail.com

${ }^{1}$ Beni - Suef University, 10th of Hafiz Ibraheem st., 6th area, Nasr City, PO Box 11371, Cairo, Egypt

Full list of author information is available at the end of the article
}

be associated with $\mathrm{OAB}$ such as urinary tract infection (UTI), obstruction, malignancy, and neurological diseases [2].

Pharmacotherapy improves OAB symptoms, reduce morbidity, and prevent complications. Muscarinic receptor antagonists are the first-line pharmacotherapeutic agents for the treatment of OAB. Anticholinergics inhibit the binding of acetylcholine to the muscarinic receptors, which suppress involuntary bladder contractions. Eventually an increase in voided volume and a decrease in micturition frequency, sensation of urgency, and number of urge incontinence episodes occur. Several antimuscarinic drugs are available for the treatment of $\mathrm{OAB}$ with significant efficacy and variable pharmacokinetic and adverse effect profiles [3]. 
The duration of antimuscarinic treatment for $O A B$ is variable in previous studies without consensus regarding the optimal duration [4]. The treatment durations in clinical studies ranged from 2 weeks to 12 months, or as the time taken to reach an optimal dose (i.e., the dose that achieved a balance between improvement in symptoms and tolerability of side effects) plus one additional week. Most overactive bladder medications take 2 to 4 weeks to be effective, and so therapy for more than 12 weeks may be longer than necessary for evaluating efficacy [5]. Many patients discontinue anticholinergics because of its side effects in the form of dry mouth, mydriasis, blurred vision, tachycardia, urine retention, and constipation [6, 7].

Lee and his colleagues studied the symptoms change after discontinuation of a successful antimuscarinic treatment in patients with $\mathrm{OAB}$ [8]. They reported a $62 \%$ symptom relapse rate three months after discontinuation of treatment. Aram and his colleagues studied the incidence and risk factors of recurrence of OAB symptoms after discontinuation of successful medical treatment. They showed that the cumulative rate of symptom recurrence was $41.3 \%$ after 3 months of discontinuation of treatment [9]. To our knowledge no studies were done about the possible effect of gradual weaning of anticholinergics in the treatment of OAB symptoms in term of recurrence of symptoms. Gradual weaning of anticholinergics may help alleviate side effects, test the proper least effective dose, and avoid the psychogenic effect of sudden stopping the drug on recurrence of symptoms.

\section{Methods}

Investigators started an open-label, prospective, twoarm, randomized controlled trial at Beni-Suef University, from January 2018 to August 2019, including 60 patients suffering from $\mathrm{OAB}$ symptoms. Patients were recently diagnosed with idiopathic OAB which was not treated prior to enrollment. Patients with UTI, diabetes, stones, tumors, or infravesical obstruction were excluded. All participants were above 18 years old and signed written informed consents. The clinical trial was registered in clinicaltrials.gov with an ID: NCT04064619. The study was accepted by our local ethics committee and patients provided an informed consent to participate in the study. Patients were allocated into two equal groups (30 patients in each group) according to a computer-generated random numeric table after exclusion of those who are not eligible or refused to be included in the study (Fig. 1).

History (stressing on medications and surgery) was reported, and patients filled an Overactive Bladder Questionnaire before and after treatment, and after weaning of treatment. All our patients were neurologically examined to exclude neurogenic OAB. Urine analysis, random blood sugar (RBS), and pelvic-abdominal ultrasonography $(\mathrm{U} / \mathrm{S})$ were performed for all our patients.

Patients were treated by solifenacin $5 \mathrm{mg}$ twice daily for 4 weeks, then the responders were assigned into two groups (Group I included half of responders who stopped treatment, while Group II included the other half of responders who were treated by solifenacin $5 \mathrm{mg}$ for further 2 weeks). Group II patients decreased the dose gradually (first week solifenacin $5 \mathrm{mg}$ once daily and second week solifenacin $5 \mathrm{mg}$ every other day). Group I patients were followed up after 1 and 3 months from stopping the drug, while group II patients were followed up after 1and 3 months from the end of gradual weaning by Overactive Bladder Questionnaire.

Stratified sampling method was used, and the sample size calculation was carried out using sample size tables of Epi Info software. Within a confidence level of $(\mathrm{CL}=95 \%)$, desired total width of confidence interval ( $W=5)$; standard deviation of the variable $(S=10.1)$; and a standard normal deviate for $\alpha=Z \alpha=1.96, W / S=0.50$. The Sample size is: $N=4 Z \alpha 2 S 2 / W 2=63$.

The collected data were tabulated, coded, and analyzed using SPSS for Windows, version 23. Continuous variables were presented as mean values \pm standard deviation (SD), and categorical variables were presented as percentages. For qualitative data, comparisons were done using Chi-squared test and Fisher test. For quantitative data, comparisons between groups and composite scores were done by $\mathrm{t}$ test for independent samples. Comparisons for Overactive Bladder Symptom Score (OABSS) were done by Mann-Whitney $U$ test for independent samples. Probability value (Pvalue) $<0.05$ was considered statistically significant.

\section{Results}

The average patient age was $44.36 \pm 18.5$ (SD) years, and $39(65.0 \%)$ patients were females. The patients' baseline evaluation of lower urinary tract symptoms by the Overactive Bladder Symptom Score (OABSS) was [8.36 1.7 (SD)] points, ranging from 6 points to 11 points (Table 1 ).

There were no statistically significant differences regarding demographic characteristics and OAB symptoms before treatment among studied patients in both groups (Table 1).

Side effects were reported in 12 patients (20\%) (Dry mouth in eight (13.3\%) and constipation in four $(6.7 \%)$ patients). Symptoms recurrence after termination of treatment was less in group II patients (Table 2).

Symptoms recurrence was higher among older patients $61.67 \pm 12.1$ (SD), while the gender of patients was not statistically related to the recurrence of symptoms (Table 3). 


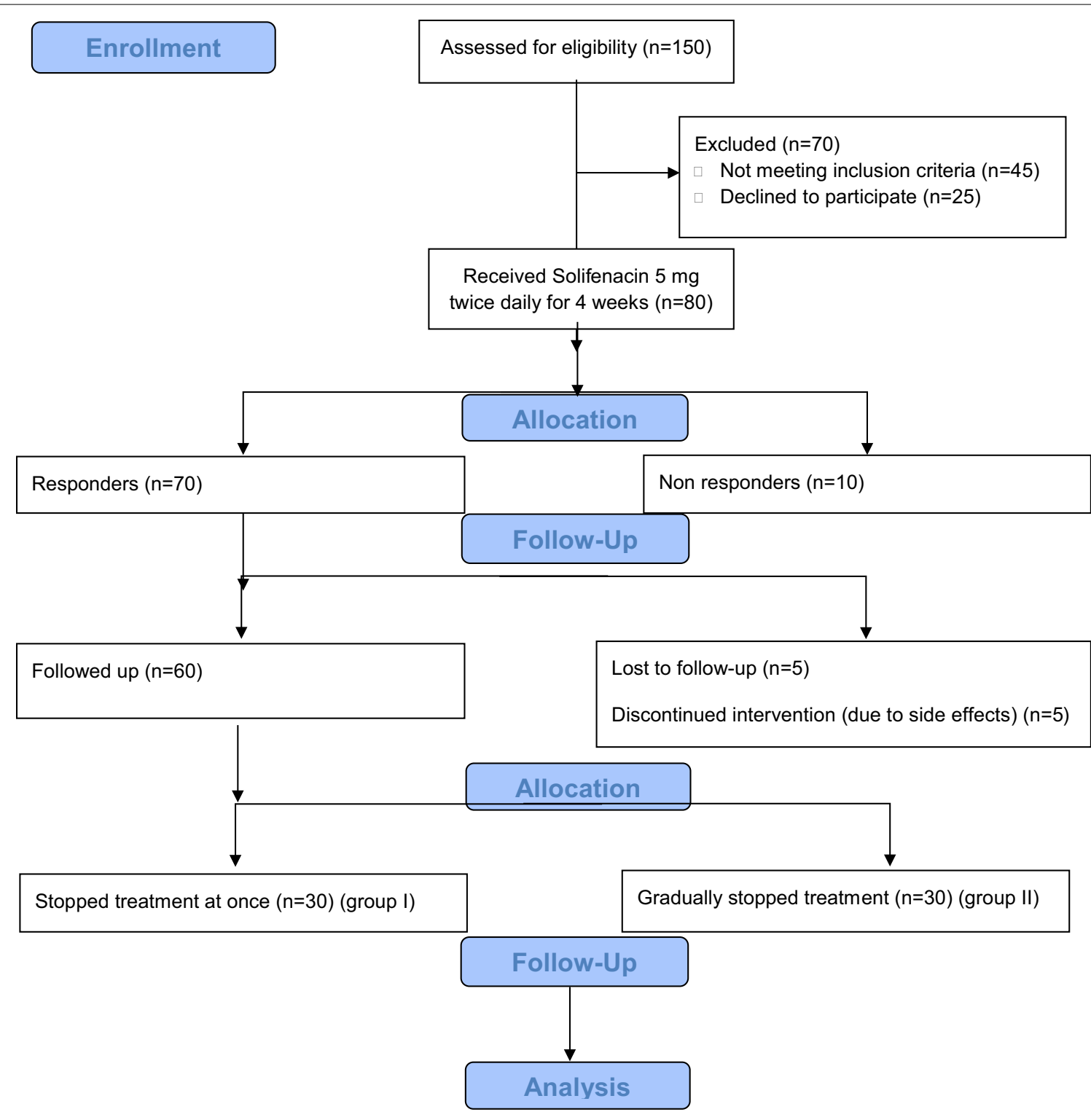

Fig. 1 Consort flow diagram of study patients

Patients who gradually stopped treatment had less recurrence of symptoms than those who immediately stopped it $(6.7 \%$ vs. $33.3 \%$, with $P$-value $=0.001)$, see Table 3.

The increase in patients' age with 0.108 years was associated with more recurrence of overactive bladder symptoms $(\mathrm{OR}=1.114 ;$ Pvalue $=0.045)$. The increase in the baseline OABSS score with 2.134 points was associated with more recurrence of overactive bladder symptoms $(\mathrm{OR}=0.118$; $P$ value $=0.025)$. Moving from gradual weaning protocol to sudden stopping protocol was associated with more recurrence of overactive bladder symptoms $(\mathrm{OR}=52.545 ; P$ value $=0.014)($ Table 3$)$.
The incidence of recurrence of symptoms was significantly higher by increasing the OABSS at the baseline level (before treatment) where the mean scores were $10.25 \pm 0.9(\mathrm{SD})$ Points $(P$ value $=0.001)($ Table 3$)$.

After 3 months of treatment, recurrence of symptoms occurred in $25(41.7 \%)$ patients (18 in group I and 7 in group II $(P=0.008))$ (Table 3$)$.

\section{Discussion}

$O A B$ adversely affects quality of life of patients2. Muscarinic receptor antagonists can relieve symptoms 3 but may cause side effects which may interfere with patient compliance and hence overall treatment efficacy. Dry 
Table 1 Demographic characteristics and OAB symptoms before treatment among studied patients in both groups

\begin{tabular}{|c|c|c|c|}
\hline \multirow{2}{*}{$\begin{array}{l}\text { Demographic } \\
\text { characteristics }\end{array}$} & \multicolumn{2}{|c|}{ Treatment protocol } & \multirow[t]{2}{*}{$P$ value } \\
\hline & $\begin{array}{l}\text { Group I } \\
\text { (sudden } \\
\text { stopping) } \\
N=30\end{array}$ & $\begin{array}{l}\text { Group II } \\
\text { (gradual } \\
\text { weaning) } \\
N=30\end{array}$ & \\
\hline \multicolumn{4}{|l|}{ Age; (years) } \\
\hline Mean $\pm S D$ & $48.10 \pm 21.7$ & $40.63 \pm 14.04$ & $0.119^{a}$ \\
\hline \multicolumn{4}{|l|}{$95 \% \mathrm{Cl}^{1}$ for Mean } \\
\hline Lower bound & 39.98 & 35.39 & \\
\hline Upper bound & 56.22 & 45.87 & \\
\hline Range (Max-Min) & $67.00(77-22)$ & $46.00(64-18)$ & \\
\hline \multicolumn{4}{|l|}{ Gender; $n(\%)$} \\
\hline Male; $n=21$ & $10(47.6)$ & $11(52.4)$ & $0.500^{b}$ \\
\hline Female; $n=39$ & $20(51.3)$ & $19(48.7)$ & \\
\hline \multicolumn{4}{|c|}{ OABSS; (before treatment) } \\
\hline Mean \pm SD & $8.60 \pm 1.8$ & $8.13 \pm 1.8$ & $0.320^{\mathrm{a}}$ \\
\hline \multicolumn{4}{|l|}{ 95\% $\mathrm{Cl}^{1}$ for Mean } \\
\hline Lower bound & 7.93 & 7.48 & \\
\hline Upper bound & 9.26 & 8.79 & \\
\hline Range (Max-Min) & $5.00(11-6)$ & $5.00(11-6)$ & \\
\hline
\end{tabular}

$195 \%$ Confidence interval of mean

a $P$ value $>0.05$ is considered non-significant by (independent sample $t$ test)

${ }^{b} P$ value $>0.05$ is considered non-significant by (Chi-square test)

Table 2 The Symptoms Recurrence rate after one month of discontinuation of the treatment Protocol and relation to demographic characteristic

\begin{tabular}{|c|c|c|c|}
\hline & \multicolumn{2}{|c|}{ Symptoms Recurrence } & \multirow[t]{2}{*}{$P$ value } \\
\hline & $\begin{array}{l}\text { No } \\
N=48\end{array}$ & $\begin{array}{l}\text { Yes } \\
N=12\end{array}$ & \\
\hline \multicolumn{4}{|c|}{ Treatment Protocol; $n$ (\%) } \\
\hline Group I; $n=30$ & $20(66.7)$ & $10(33.3)$ & $0.001^{*}$ \\
\hline Group $\| ; n=30$ & $28(93.3)$ & $2(6.7)$ & \\
\hline \multicolumn{4}{|l|}{ Age; (years) } \\
\hline qMean $\pm S D$ & $40.04 \pm 17.4$ & $61.67 \pm 12.1$ & $0.001^{*}$ \\
\hline \multicolumn{4}{|l|}{$95 \% \mathrm{Cl}^{1}$ for Mean } \\
\hline Lower bound & 35.00 & 54.00 & \\
\hline Upper bound & 45.08 & 69.32 & \\
\hline Range (Max-Min) & $65.00(75-10)$ & $35.00(77-42)$ & \\
\hline \multicolumn{4}{|l|}{ Gender; $n(\%)$} \\
\hline Male; $n=21$ & $18(85.7)$ & $3(14.3)$ & $0.325^{\mathrm{a}}$ \\
\hline Female; $n=39$ & $30(76.9)$ & $9(23.1)$ & \\
\hline
\end{tabular}

$195 \%$ Confidence Interval of Mean

${ }^{*} P$ value $\leq 0.05$ is considered significant by (independent sample $t$ test)

a $P$ value $>0.05$ is considered non-significant by (Chi-square test) mouth, the most commonly reported, is common even with newer formulations such as extended-release oxybutynin and extended-release tolterodine7. Thus, there is a need for new treatment options that can provide symptom relief with improved tolerability. The least proper dose (to avoid side effects), duration, and the way of stopping treatment need to be investigated. Increasing the dose gradually was studied in the (SUNRISE, solifenacin in the treatment of urgency symptoms of OAB in a rising dose, randomized, placebo-controlled, double-blind, efficacy trial) [10]. They concluded that solifenacin was better than placebo, and dose escalation was more beneficial than placebo increase [11].

We studied the effect of weaning of solifenacin in treatment of OAB patients as regards efficacy, side effects, and symptoms recurrence. To our knowledge, the effect of weaning of anticholinergics on recurrence of OAB symptoms was not studied before. We thought weaning can detect least effective dose. But in our study we concentrated on the effects of weaning the drug on the rate of symptoms recurrence. We found a significant improvement of OAB symptoms after use of solifenacin in 70 out of $80(87.5 \%)$ patients enrolled in the study, a result close to that of Oresković and his colleagues who reported significant improvement in $92.2 \%$ of patients treated with solifenacin [12].

In our study, we divided the responding patients into two groups after the initial improvement of OAB symptoms. In group II (gradual weaning), the incidence of symptoms recurrence after one month of discontinuation of treatment was only $6.7 \%$, while it was $33.3 \%$ in group I patients $(P=0.001)$, which indicate the significance of gradual weaning in preventing early symptom recurrence.

Chapple and his colleagues reported that the flexible dosing of solifenacin is more effective in treating $O A B$ compared with the highest licensed dose of extended release tolterodine. The flexible dosing of solifenacin may further increase its efficacy, and allow treatment regimens to be designed according to patient needs, thus improving patient compliance and satisfaction [13].

Basra and his colleagues showed that reducing the frequency of medication doses might improve adherence to therapy. Once-daily dosing of medication improves patient's adherence more than twice, three, or more times per day. This is particularly important in elderly patients with $\mathrm{OAB}$ who may have comorbidities or concomitant therapies. Dose flexibility allows patients to titrate symptom improvement against side effects [14].

Choo and his colleagues reported that the re-treatment rate was $35.3 \%$ after the discontinuation of antimuscarinic therapy [15], while Aram Kim and his colleagues reported a $23.8 \%$ cumulative rate of symptom recurrence 
Table 3 Logistic Regression Analysis of Independent Predictors of Symptoms Recurrence after one month of discontinuation of Treatment

\begin{tabular}{|c|c|c|c|c|c|}
\hline & \multirow[t]{2}{*}{ B } & \multirow[t]{2}{*}{ P-Value } & \multirow[t]{2}{*}{ OR } & \multicolumn{2}{|c|}{$95 \%$ C.I. for OR } \\
\hline & & & & Lower & Upper \\
\hline Constant & 12.572 & & & & \\
\hline Age (years) & 0.108 & $0.045^{*}$ & 1.114 & 0.947 & 1.312 \\
\hline OABSS at the baseline (before treatment) & 2.134 & $0.025^{*}$ & 0.118 & 0.018 & 0.767 \\
\hline OABSS 1 month after treatment & -1.680 & 0.068 & 0.186 & 0.017 & 2.028 \\
\hline \multicolumn{6}{|l|}{ Treatment protocol } \\
\hline Group I (sudden stopping) & 3.962 & $0.014^{*}$ & 52.545 & 1.122 & 2460.225 \\
\hline Group II (gradual weaning) & REF & & & & \\
\hline \multicolumn{6}{|c|}{ Model $X 2=31.578 ; P$-value $\leq 0.001$ correctly predicted $(38.3 \%)$} \\
\hline
\end{tabular}

$O R=$ odds ratio; $\mathrm{Cl}=$ confidence interval; $R E F=$ reference group

after 1 month from discontinuation of antimuscarinic agents [9].

Our study showed that symptoms recurred in $41.7 \%$ of patients after 3 months of discontinuation of treatment (group $\mathrm{I}=60 \%$ and group $\mathrm{II}=23.3 \%$ ). Our results were similar to those of Kim and coworkers who showed that the cumulative rate of symptom recurrence was $41.3 \%$ after 3 months of discontinuation of treatment9, while the symptom relapse rate was $62 \%$ three months after discontinuation of treatment in the study of Lee and coworkers [8].

By comparing patients with or without recurrence of OAB symptoms in our study, we found that patients with recurrent symptoms are significantly older and have significantly higher baseline OABSS when compared with patients without recurrence. These findings are similar to those of Choo and his colleagues who showed that patients in the re-treatment group were significantly older and had higher initial urgency scores than those requiring no further treatment [15]. Hsiao and coworkers reported that in patients with baseline $\mathrm{OABSS} \geq 7$, alternative treatment may be considered earlier, if there is no response to antimuscarinic therapy [4]. In contrast, Lee and his colleagues [8] and Kim and his colleagues [9] found no association between symptom recurrence and patients' age.

In our study, the reported side effects included dry mouth in eight patients (13.3\%) and constipation in four patients (6.7\%). This is in agreement with Chapple and his colleagues who reported dry mouth in $14 \%$ of patients treated with the 5 and $10 \mathrm{mg}$ solifenacin [16]. Also, Cardozo and her colleagues showed that adverse events with solifenacin $5 / 10 \mathrm{mg}$ were mainly dry mouth $(15.8 \%)$ and constipation $(6.9 \%)$ [10].

We think that weaning will help in detecting the least effective dose in patients with symptoms recurrence.
Weaning may be more flexible to be every other day dosing or even twice weekly. Further larger randomized studies may be needed to test the effect of different low dose intermittent treatments on prevention of symptoms recurrence. Weaning may have a psychogenic role which makes patients feel confident that they will not have symptoms recurrence. Weaning may also help in detecting the optimum duration of treatment and design it according to patient's needs, because some patients may need higher doses or longer durations of treatment.

\section{Conclusion}

Our results support the importance of gradual weaning of solifenacin after improvement of OAB symptoms in decreasing the recurrence rate of symptoms. We believe that this approach will improve the results of treatment added the building up of the dose approach. We could not find previous studies to assess the effect of weaning of anticholinergics in treatment of OAB.

\section{List of Abbreviations}

OAB: overactive bladder; ICS: International Continence Society; UTI: urinary tract infection; RBS: random blood sugar; U/S: pelvic-abdominal ultrasonography; CL: confidence level; W: Width of confidence interval; S: Standard deviation of the variable; SD: standard deviation; OABSS: Overactive Bladder Symptom Score; $P$ value: probability value (Pvalue); OR: odds ratio; Cl: confidence interval; REF: reference group; Max: maximum; Min: minimum; SUNRISE: solifenacin in the treatment of urgency symptoms of $O A B$ in a rising dose, randomized, placebo-controlled, double-blind, efficacy trial.

\section{Acknowledgements}

We would like to thank the local faculty authorities for supporting and funding the current research.

\section{Authors' contributions}

All authors have read and approved the manuscript. AA contributed to conception and design, analysis and interpretation of data, critical revision of the manuscript for important intellectual content, and supervision. AAA was involved in analysis and interpretation of data and supervision. AM, ME, and $A E$ were involved in acquisition of data. AR, AME, and $A E A$ contributed to drafting of the manuscript. OS, AL were involved in critical revision of the 
manuscript for important intellectual content. KM contributed to statistical analysis. AMA was involved in administrative, technical, or material support. EG was involved in obtaining funds. AMM was involved in acquisition of data, analysis and interpretation of data, and supervision. RI was involved in supervision.

\section{Funding}

Funding of the study was from the local faculty authorities.

\section{Availability of data and material}

The datasets used and/or analyzed during the current study are available from the corresponding author on reasonable request.

\section{Ethics approval and consent to participate}

The study protocol was approved by the ethics committee of Beni-Suef faculty of medicine. Approval number is not available. Written informed consent was obtained from all patients

\section{Consent for publication}

No individual person's data are included in our manuscript.

\section{Competing interests}

None of the contributing authors have any conflict of interest, including specific financial interests or relationships and affiliations relevant to the subject matter or materials discussed in the manuscript.

\section{Author details}

${ }^{1}$ Beni - Suef University, 10th of Hafiz Ibraheem st., 6th area, Nasr City, PO Box 11371, Cairo, Egypt. ${ }^{2}$ Fayoum University, Faiyum, Egypt. ${ }^{3}$ Minia University Hospital, Minya, Egypt.

Received: 17 August 2020 Accepted: 27 November 2020

Published online: 14 December 2020

\section{References}

1. Haylen BT et al (2012) International Urogynecological Association (IUGA)/ International Continence Society (ICS) joint terminology and classification of the complications related to native tissue female pelvic floor surgery. NAU Neurourol Urodyn 31(4):406-414

2. Milsom I, Abrams P, Cardozo L et al (2001) How widespread are the symptoms of an overactive bladder and how are they managed? A population-based prevalence study. BJU Int 87:760-766

3. Herbison P, Hay-Smith J, Ellis G, Moore K (2003) Effectiveness of anticholinergic drugs compared with placebo in the treatment of overactive bladder: systematic review. BMJ 326:841-844

4. Hsiao S-M, Liao C-H, Lin H-H, Kuo H-C (2015) Duration of antimuscarinic administration for treatment of overactive bladder before which one can assess efficacy: an analysis of predictive factors. Int Neurourol J 19(3):171-177
5. Novara G, Galfano A, Secco S, D’Elia C, Cavalleri S, Ficarra V et al (2008) A systematic review and meta-analysis of randomized controlled trials with antimuscarinic drugs for overactive bladder. Eur Urol 54:740-763

6. Yokoyama T et al (2013) Long-term safety and efficacy of two different antimuscarinics, imidafenacin and solifenacin, for treatment of overactive bladder: a prospective randomized controlled study. Urol Int 90(2):161-167

7. Benner JS, Nichol MB, Rovner ES et al (2010) Patient reported reasons for discontinuing overactive bladder medication. BJU Int 105:1276

8. Lee YS, Choo MS, Lee JY, Oh SJ, Lee KS (2011) Symptom change after discontinuation of successful antimuscarinic treatment in patients with overactive bladder symptoms: a randomised, multicentre trial. Int J Clin Pract 65(9):997-1004

9. Aram K, Kyu-Sung L, Tae BK et al (2017) Incidence and risk factors of recurrence of overactive bladder symptoms after discontinuation of successful medical treatment. Investig Clin Urol 58(1):42-47

10. Linda C, Elke H, Rodolfo M, Pedro A, Luc D, Mark S, Ted D, MarkW, John B, for the SUNRISE Study Group (2008) Solifenacin in the treatment of urgency and other symptoms of overactive bladder: results from a randomized, double-blind, placebo-controlled, rising-dose trial. BJUI 102(9):1120-1127

11. Linda C, Elke H, Rodolfo M, Pedro A, Luc D, Mark S, Ted D, Mark W, John B, SUNRISE Study Group (2008) Solifenacin in the treatment of urgency and other symptoms of overactive bladder: results from a randomized, double-blind, placebo-controlled, rising-dose trial. BJU Int 102(9):11201127. https://doi.org/10.1111/j.1464-410x.2008.07939.x

12. Oresković S, But I, Banović M, Goldstajn MS (2012) The efficacy and safety of solifenacin in patients with overactive bladder syndrome. Coll Antropol. 36(1):243-248

13. Chapple CR, Fianu-Jonsson A, Indig M, Khullar V, Rosa J, Scarpa RM, Mistry A, Wright DM, Bolodeoku J, STAR study group (2007) Treatment outcomes in the STAR study: a subanalysis of solifenacin $5 \mathrm{mg}$ and tolterodine ER 4 mg. Eur Urol 52(4):1195-1203

14. Basra RK, Wagg A, Chapple C, Cardozo L, Castro-Diaz D, Pons ME, Kirby M, Milsom I, Vierhout M, Van Kerrebroeck P, Kelleher C (2008) A review of adherence to drug therapy in patients with overactive bladder. BJU Int 102(7):774-779

15. Choo MS, Song C, Kim JH, Choi JB, Lee JY, Chung BS, Lee KS (2005) Changes in overactive bladder symptoms after discontinuation of successful 3-month treatment with an antimuscarinic agent: a prospective trial. J Urol 174(1):201-204

16. Chapple CR, Araño P, Bosch JL, De Ridder D, Kramer AE, Ridder AM (2004) Solifenacin appears effective and well tolerated in patients with symptomatic idiopathic detrusor overactivity in a placebo- and tolterodinecontrolled phase 2 dose-finding study. BJU Int 93(1):71-77

\section{Publisher's Note}

Springer Nature remains neutral with regard to jurisdictional claims in published maps and institutional affiliations.

\section{Submit your manuscript to a SpringerOpen ${ }^{\circ}$ journal and benefit from:}

- Convenient online submission

- Rigorous peer review

- Open access: articles freely available online

- High visibility within the field

- Retaining the copyright to your article

Submit your next manuscript at $\boldsymbol{\nabla}$ springeropen.com 